\title{
Mechanisms of deep brain stimulation for obsessive compulsive disorder: effects upon cells and circuits
}

\author{
Sarah K. Bourne ${ }^{*}{ }^{\dagger}$, Christine A. Eckhardt ${ }^{*}$, Sameer A. Sheth and Emad N. Eskandar
}

Department of Neurosurgery, Massachusetts General Hospital, Boston, MA, USA

\section{Edited by:}

John T. Gale, Cleveland Clinic, USA

\section{Reviewed by:}

Alexander M. Papanastassiou,

University of Texas Health Science

Center San Antonio, USA

Darlene Floden, Cleveland Clinic,

USA

\section{${ }^{*}$ Correspondence:}

Christine A. Eckhardt and Sarah K.

Bourne, Department of

Neurosurgery, Massachusetts

General Hospital, Boston,

MA 02114, USA.

e-mail: ceckhardt@partners.org;

sarah.k.bourne@vanderbilt.edu

tThese authors equally contributed to this work.

\begin{abstract}
Deep brain stimulation (DBS) has emerged as a safe, effective, and reversible treatment for a number of movement disorders. This has prompted investigation of its use for other applications including psychiatric disorders. In recent years, DBS has been introduced for the treatment of obsessive compulsive disorder (OCD), which is characterized by recurrent unwanted thoughts or ideas (obsessions) and repetitive behaviors or mental acts performed in order to relieve these obsessions (compulsions). Abnormal activity in cortico-striato-thalamo-cortical (CSTC) circuits including the orbitofrontal cortex (OFC), anterior cingulate cortex (ACC), ventral striatum, and mediodorsal (MD) thalamus has been implicated in OCD. To this end a number of DBS targets including the anterior limb of the internal capsule (ALIC), ventral capsule/ventral striatum (VCNS), ventral caudate nucleus, subthalamic nucleus (STN), and nucleus accumbens (NAc) have been investigated for the treatment of OCD. Despite its efficacy and widespread use in movement disorders, the mechanism of DBS is not fully understood, especially as it relates to psychiatric disorders. While initially thought to create a functional lesion akin to ablative procedures, it is increasingly clear that DBS may induce clinical benefit through activation of axonal fibers spanning the CSTC circuits, alteration of oscillatory activity within this network, and/or release of critical neurotransmitters. In this article we review how the use of DBS for OCD informs our understanding of both the mechanisms of DBS and the circuitry of OCD. We review the literature on DBS for OCD and discuss potential mechanisms of action at the neuronal level as well as the broader circuit level.
\end{abstract}

Keywords: deep brain stimulation, obsessive compulsive disorder, neuromodulation, cortico-striatothalamocortical circuit

\section{INTRODUCTION}

Approximately 2-3\% of Americans suffer from OCD, a mental illness characterized by chronic intrusive thoughts (obsessions) and/or repetitive behaviors (compulsions). Half of these patients experience severe disease that seriously impairs their occupational, academic, and/or interpersonal functioning (Kessler et al., 2005). Although behavioral therapy and medical management benefit some patients, $20-40 \%$ of OCD patients-often those most severely affected-remain refractory to treatment (Skoog and Skoog, 1999). Lesion procedures such as anterior capsulotomy and dorsal cingulotomy have been available to patients with refractory OCD for over 40 years (Dougherty et al., 2002; Mian et al., 2010), however, these procedures have the disadvantage of being irreversible. In 1999, DBS was introduced as a neurosurgical treatment for OCD (Nuttin et al., 1999) with the advantage of being reversible and adjustable. In early clinical trials, twothirds of OCD patients treated with DBS showed a statistically significant improvement in symptoms and global functioning (Greenberg et al., 2010a).

Despite the clinical benefit of DBS, the mechanisms underlying its therapeutic success remain unclear. First hypothesized to mimic ablative procedures and produce the functional equivalent of a lesion (Nuttin et al., 1999), animal and human studies have indicated a more complex neurophysiological effect. OCD is thought to arise from abnormal neural activity in the CSTC circuit, a network involving ACC, OFC, dorsolateral prefrontal cortex (DLPFC), ventral striatum, MD thalamus, and amygdala (Rauch et al., 2006; Rotge et al., 2008, 2010; Haber and Brucker, 2009; den Braber et al., 2010). Studies of DBS have elucidated local cellular mechanisms that influence the function of both the stimulated target area and distant regions, which may ultimately modulate pathological network activity in the CSTC circuit. In this article, we first review the pathophysiology of OCD before examining the basic mechanisms of action of DBS and applying what is known about these mechanisms to understand how DBS functions in OCD. We analyze the results of neuroimaging studies, intraoperative human recordings, and in vivo and in vitro animal studies of DBS in order to inform our knowledge of the mechanisms of DBS and how this increases our understanding of the pathophysiology of OCD.

\section{PATHOLOGY OF OCD}

The CSTC-based theory of behavioral control serves as a useful model for the investigation of mental health disorders such 


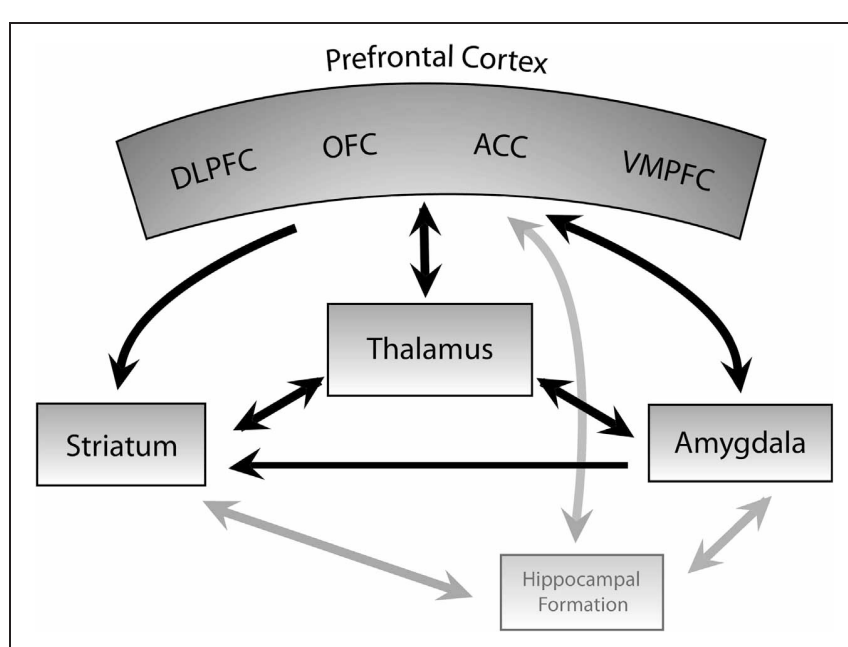

FIGURE 1 | Cortico-striato-thalamocortical circuit. Schematic diagram of the cortico-striato-thalamocortical (CSTC) circuit, which is implicated in the pathophysiology of OCD. In DBS for OCD, activity within this circuit is thought to be modulated by high frequency stimulation. DLPFC, dorsolateral prefrontal cortex; ACC, anterior cingulate cortex; OFC, orbitofrontal cortex; VMPFC, ventromedial prefrontal cortex. Arrowheads indicate direction of neural input. Black lines represent connections among the major structures implicated in DBS for OCD; gray lines indicate additional connections.

as OCD (Figure 1). OFC is a critical cortical component of the CSTC implicated in OCD, and extensive evidence links OFC dysfunction to OCD. Positron emission tomography (PET) studies in patients with OCD have identified increased metabolism in OFC in the resting state (Baxter et al., 1987, 1988) and increased activity with symptom provocation has also been observed with PET and functional magnetic resonance imaging (fMRI). (McGuire et al., 1994; Rauch et al., 1994; Adler et al., 2000). Additionally, OFC PET metabolism elevation is correlated with anxiety levels in OCD patients (Swedo et al., 1989). OFC activation with obsessions is not limited to the pathologic state; increased OFC activity is also seen with PET during stimulation of obsessive thoughts in healthy controls (Cottraux et al., 1996). A PET study showed that OFC metabolism decreases with pharmacologic treatment, and this decrease correlates with several measures of improvement in OCD symptoms (Swedo et al., 1992). The medial OFC (mOFC) and lateral OFC (lOFC) may be differentially involved in OCD. The $\mathrm{mOFC}$ is active in emotional regulation and positive valence processing while the lOFC processes negative reinforcers and fear response (Kringelbach and Rolls, 2004). In OCD, there may be increased lOFC and decreased mOFC activity (Milad and Rauch, 2007), although findings are somewhat inconsistent (Milad and Rauch, 2011). The OFC is also involved in behavioral planning and expected reward valuation. Dysfunctions of these processes are likely involved in the repetitive compulsions and driving obsessions of OCD, and may be represented by the altered OFC activity seen in this disease.

ACC plays a role in motivation and conflict monitoring, as well as determining discrepancies between desired and anticipated state (Graybiel and Rauch, 2000; Del Casale et al., 2011). These functions are important in OCD, in which obsessions and compulsions may be in part due to dysfunctional reward signaling and aberrant signaling of conflict between desired and current state. PET and single photon emission computed tomography (SPECT) studies have demonstrated increased ACC metabolism in OCD patients at rest (Swedo et al., 1989; Machlin et al., 1991; Perani et al., 1995) and PET and fMRI studies have also found increased ACC activity with symptom provocation (Rauch et al., 1994; Breiter et al., 1996; Adler et al., 2000) and error or high conflict trials on an interference processing task (Fitzgerald et al., 2005; Maltby et al., 2005; Schlosser et al., 2010). ACC metabolism measured with PET decreases following treatment with selective serotonin reuptake inhibitors (SSRIs), correlating with decreases in Yale Brown Obsessive Compulsive Scale (Y-BOCS) score (Perani et al., 1995), a commonly used metric of OCD severity. Interestingly, increased PET ACC metabolism prior to treatment is seen in clomipramine non-responders (Swedo et al., 1989), perhaps representing a degree of severity or a marker of different pathological underpinnings resistant to pharmacologic therapy. Lesion of the dorsal anterior cingulate (cingulotomy) can result in long-term improvement in OCD symptoms in patients refractory to pharmacologic and behavior therapy (Dougherty et al., 2002). The cingulate cortex has close connections to motor cortex and participates in action selection. Graybiel and Rauch suggest that OFC and ACC together have a strong influence on perceived value and corresponding action selection (Graybiel and Rauch, 2000). The altered activity of both of these structures seen in OCD may represent abnormal function and interaction of OFC and ACC in OCD contributing to dysfunctional valuation and repetitive actions characteristic of OCD.

The basal ganglia participate in multiple parallel corticobasal ganglia circuits and are important in motor inhibition and release. It has been hypothesized that an analogous role exists in cognitive circuits in parallel with motor circuitry and may be involved in the pathophysiology of OCD (Saxena et al., 1998; Graybiel and Rauch, 2000). In particular, the caudate nucleus has been implicated in OCD. The caudate plays a role in procedural learning and may contribute to abnormal processing of behavioral sequences generated by frontal subcortical circuits that have been hypothesized to exist in OCD (Graybiel and Rauch, 2000; Saxena and Rauch, 2000). Structural studies have shown altered caudate volume in OCD (Luxenberg et al., 1988; Scarone et al., 1992; Robinson et al., 1995), with decreased N-acetyl-aspartate (NAA), thought to be a marker of neuronal density, in caudate and putamen (Ebert et al., 1997; Bartha et al., 1998). Functionally, caudate activity measured with PET is increased at rest (Baxter et al., 1987, 1988) and increased activity during symptom provocation has been observed with PET and fMRI (Rauch et al., 1994; Breiter et al., 1996; Simon et al., 2010), correlating with symptom intensity (McGuire et al., 1994), with decreased activity measured with PET correlating with improvement in symptoms following pharmacologic (Benkelfat et al., 1990) or behavioral therapy (Baxter et al., 1992). OCD patients have decreased dopamine D2 receptor binding (Denys et al., 2004) and increased dopamine transporter density (van der Wee et al., 2004) in the caudate, suggesting dysfunction of this structure and perhaps altered dopaminergic tone in OCD. 
As part of the involved CSTC circuit, the thalamus has also been studied in OCD, with some PET study evidence showing increased activity in the resting state (Swedo et al., 1989; Perani et al., 1995) and with increased blood flow measured with $\mathrm{H}_{2}{ }^{15} \mathrm{O}$ PET correlating with symptom intensity during symptom provocation (McGuire et al., 1994). Prior to treatment, OCD patients showed correlation of OFC activity measured with PET with ipsilateral caudate and thalamus activity, but this correlation disappeared after successful pharmacologic or behavioral therapy (Baxter et al., 1992; Schwartz et al., 1996), suggesting that abnormal signaling between these regions may be involved in OCD pathophysiology (Modell et al., 1989).

In the medial temporal cortex, the hippocampus and amygdala bear connections to each other and the prefrontal cortex (PFC), and these regions may play a role in the pathophysiology of OCD. The amygdala is critically involved in the association of external stimuli with emotional value and the acquisition of conditioned fear responses (Aggleton, 1993; Cahill and McGaugh, 1998). The hippocampus integrates spatial and affective information (Sesack and Grace, 2010) and is necessary for context-dependent fear conditioning (Fanselow, 2000; Maren and Quirk, 2004) and the behavioral response to stress (Bouton and Bolles, 1979; Bouton and King, 1983), among other functions. Thus, abnormal activity in these structures may underlie the anxiety triggered by provocative simuli which often accompanies a patient's urge to perform compulsions.

Multiple imaging studies have highlighted functional and structural abnormalities in these regions among patients with OCD as compared to healthy controls. A positive correlation between symptom intensity and blood flow in the left hippocampus has been demonstrated using PET (McGuire et al., 1994). fMRI has also revealed increased activation of the medial temporal cortex when unmedicated patients are exposed to provocative stimuli that triggers OCD symptoms (Adler et al., 2000). In structural MRI studies, the mean volume of the hippocampus and amygdala is decreased among OCD patients (Kwon et al., 2003), and OCD severity appears to be correlated with left hippocampal volume (Atmaca et al., 2008; Atmaca, 2011). MRI has also shown bilateral hippocampal shape deformity, which may reflect altered neural connections (Hong et al., 2007). Researchers employing proton magnetic resonance spectroscopy found decreased NAA/CR (N-acetylaspartate/creatine) and NAA/CHO (N-acetyl-aspartate/choline) ratios (Atmaca et al., 2009). Reductions in NAA, a primarily intracellular metabolite, are thought to indicate a loss of neurons. Increases in creatine, an energetic marker, and $\mathrm{CHO}$, a component of some phospholipids, are thought to reflect membrane breakdown. Thus, these ratios suggest hippocampal degeneration.

Despite these results, not all imaging studies have identified a significant effect in the amygdala and/or hippocampus (Busatto et al., 2000; Saxena et al., 2004). These discrepancies may arise from variations in the pathophysiology of OCD depending on severity or subtype of obsessions. In a study using proton magnetic resonance spectroscopy, patients with autogenous obsessions, which do not emerge in response to identifiable external stimuli, had elevated NAA/CR ratios in the amygdala and hippocampus. This increase was not observed in the same brain regions of healthy controls or patients with reactive obsessions, a subtype of OCD in which obsessions are evoked by specific external stimuli (Besiroglu et al., 2011). In contrast, altered energy metabolism was found in the ACC, a commonly implicated brain region in the pathology of $\mathrm{OCD}$, in patients with either subtype of OCD. These results suggest that patient categorization within OCD may reveal effects masked when OCD is studied as a homogenous disorder. Such consideration of heterogeneity may be most important when investigating regions that have only been weakly implicated in OCD, but may nonetheless significantly affect pathology and, in turn, treatment, in certain forms of OCD. Although the hippocampus and amygdala have received less attention in the literature than ACC or OFC, these regions may garner greater focus in the future, given recent evidence that the ameliorating effect of OCD treatments may arise, in part, from hippocampal neurogenesis (Derrick et al., 2000; BruelJungerman et al., 2006; Chun et al., 2006; Kitamura et al., 2010; Stone et al., 2011).

\section{MECHANISMS OF ACTION OF DBS}

The longest established application of DBS is for the treatment of Parkinson's disease (PD). Accordingly, the majority of studies of the local and cellular effects of high frequency stimulation (HFS) pertain to stimulation of STN or globus pallidus internus (GPi), the two structures targeted for treatment of this disease. Nonetheless, some mechanisms may be generalizable to DBS for OCD, thus warranting their review (Table 1).

\section{Table 1 | Mechanisms of action of DBS.}

\section{Mechanisms of action of DBS}

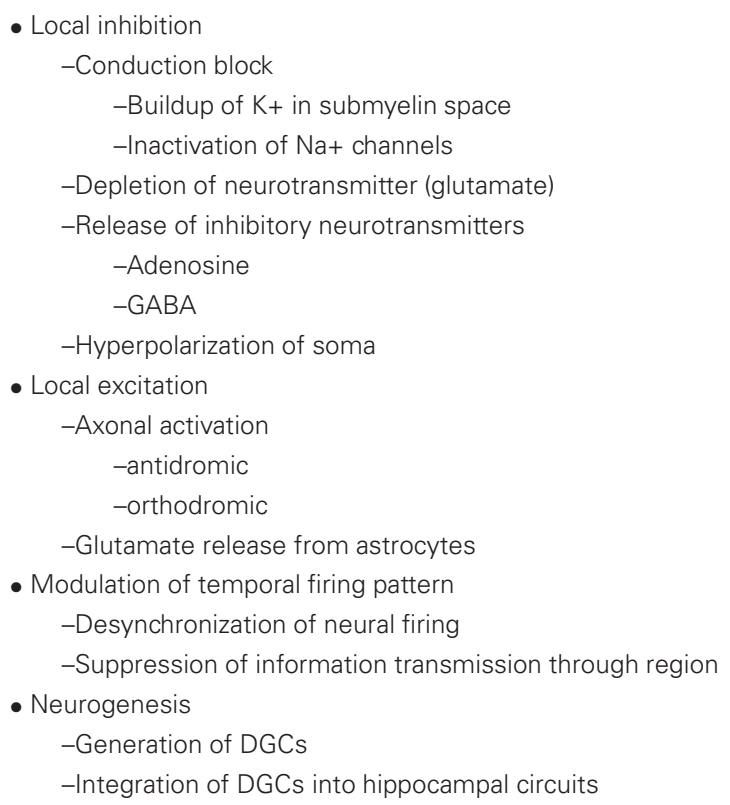

DGCs: dentate gyrus cells. 


\section{DBS AS FUNCTIONAL LESION-MECHANISMS OF LOCAL INHIBITION}

The clinical outcomes of ablative neurosurgical techniques, such as anterior capsulotomy and cingulotomy, resemble those of DBS, which has prompted comparisons of DBS to a lesion (Nuttin et al., 1999). Inactivation of the STN via injections of lidocaine or the gamma-aminobutyric acid (GABA) agonist muscimol alleviates parkinsonian motor symptoms in 1-Methyl-4-phenyl-1,2,3,6tetrahydropyridine (MPTP) treated primates (Wichmann et al., 1994) and humans with PD (Levy et al., 2001). Muscimol injection into the ventralis intermedius thalamus of humans has also been shown to alleviate tremor (Pahapill et al., 1999), suggesting that DBS might achieve its similar therapeutic effect through local inhibition (Table 1). Single unit extracellular recordings in animal studies of HFS, the experimental equivalent of DBS, of the STN, GPi, and thalamus have shown suppression of neuronal activity in the targeted region (Benazzouz et al., 1995; Boraud et al., 1996; Benazzouz and Hallett, 2000; Tai et al., 2003; Meissner et al., 2005). Human studies of DBS of the STN (Filali et al., 2004; Welter et al., 2004) and GPi (Dostrovsky et al., 2000) using single unit recordings have also shown local inhibition. However, not all studies have corroborated these results; single unit recordings conducted during DBS of STN in humans did not show suppression of the stimulated region (Carlson et al., 2010). Such discrepancies are quintessential of the study of DBS thus far, which indicates that DBS may evoke multiple effects, with the weight of any given mechanism varying.

Evidence for different mechanisms of local inhibition has emerged, including conduction block, depletion of neurotransmitter, and activation of inhibitory inputs. HFS may cause a conduction block via a buildup of $\mathrm{K}+$ in the submyelin space (Bikson et al., 2001; Lian et al., 2003; Bellinger et al., 2008) and axonal depolarization that inactivates $\mathrm{Na}+$ channels (Beurrier et al., 2001; Kiss et al., 2002). Depolarization may also result in glutamatergic release and subsequent depression due to depletion of the neurotransmitter pool, as has been shown in in vitro studies of HFS of the thalamus in rodent brain slices (Urbano et al., 2002; Anderson et al., 2004; Iremonger et al., 2006).

Release of inhibitory neurotransmitters may also suppress neuronal activity. HFS has been shown to evoke release of adenosine triphosphate (ATP) in the in vitro rodent slice, resulting in increased extracellular adenosine levels and suppression of thalamic activity via activation of the adenosine Al receptor (Bekar et al., 2008). GABAergic afferent inputs may also play a signficant role in stimulation induced inhibition, especially considering that stimulation more readily activates axon terminals than local cells near an electrode (Baldissera et al., 1972; Jankowska et al., 1975; Gustafsson and Jankowska, 1976). Lee and colleagues (2004) found that STN stimulation in vitro causes local GABA mediated postsynaptic potentials. Microstimulation of the GPi appears to cause preferential activation of GABAergic axons (Dostrovsky et al., 2000), possibly due to the predominance of GABAergic over glutamatergic terminals in the GPi (Shink and Smith, 1995) indeed, while stimulating in a region with greater glutamatergic inputs, the thalamus, Dostrovsky and colleagues (1999) observed postsynaptically mediated excitation. Results such as theseexcitation in one brain region, inhibition in another-exemplify the diversity of findings regarding the mechanisms of DBS, indicating that the neurophysiological effects of DBS are more nuanced than those of a lesion. The overall effect may depend in part on characteristics of the region being stimulated and the convergence of opposing mechanisms.

\section{NEUROPHYSIOLOGICAL RESPONSE OF A NEURON TO HFS}

Computational models suggest that DBS has a decoupling effect within the individual neuron, causing inhibition of the soma and excitation of the axon (McIntyre et al., 2004; Miocinovic et al., 2006). The influence of an electric field on a cell is related to the second derivative of the extracellular potential distribution along each process of a neuron (McNeal, 1976; Rattay, 1986). As a result, stimulation both hyperpolarizes and depolarizes a neuron, depending on the geometric relationship of the electrode to the cell (McIntyre and Grill, 1999; Rattay, 1999). With the complex three-dimensional branching of the dendritic arbor, neurons experience hyperpolarization and depolarization, with the soma tending to hyperpolarize and the axon hillock depolarizing, potentially triggering an action potential. The concentration of inhibitory inputs on the proximal dendrites and soma may also enhance this hyperpolarization of the soma, particularly since axon terminals, including GABAergic inputs, are readily activated by HFS (McIntyre et al., 2004). Models have also demonstrated that HFS can cause antidromic activation and "re-orthodromic" activation, in which the action potential propagates into the terminal. Antidromic activation only occurs when the diameters of each axonal process fall under a threshold, and propagation significantly depends on the geometry of the node of Ranvier at the axonal bifurcation (Grill et al., 2008).

Experimental results in the rodent and human accord with these models; electrical stimulation in gray matter activates axons but not cell bodies (Nowak and Bullier, 1998). With HFS of the STN, some STN neurons exhibit an increased discharge rate (Tai et al., 2003), which is hypothesized to arise from activation of glutamatergic afferents. Electrophysiological recordings during HFS of the STN have also shown increased output to recipient nuclei from the targeted region, through either orthodromic or antidromic activation (Windels et al., 2000; Hashimoto et al., 2003; Maurice et al., 2003). Li and colleagues (2007) reported antidromic activation of deep layer cortical neurons during HFS of the STN. With simultaneous multisite LFP recordings during HFS of the NAc, researchers observed inhibition of the OFC, which they linked to antidromic activation of corticostriatal projections to cortical inhibitory interneurons (McCracken and Grace, 2007). Inhibition of the output structures of the basal ganglia, including the substantia nigra pars reticulara $(\mathrm{SNr})$ and GPi, has also been demonstrated in rodents and may arise through a similar mechanism (Burbaud et al., 1994; Benazzouz et al., 1995; Benazzouz and Hallett, 2000; Anderson et al., 2003). Thus, activation of axons may have distal effects, inducing overall excitation or inhibition through stimulation of inhibitory interneurons.

\section{MODULATION OF TEMPORAL FIRING PATTERN}

Rather than inducing complete local inhibition, DBS may partially dampen neural activity and reshape firing patterns. In the diseased state, target regions often display abnormal firing 
patterns. In rats with substantia nigra pars compacta (SNC) lesion induced parkinsonian behaviors, STN neurons exhibit an irregular bursting pattern as compared to normal rats, despite equivalent mean firing rates (Tai et al., 2003). Moreover, HFS of the rodent STN has been shown to alter the bursting pattern of STN neurons, with no inhibition of the region's intrinsic activity (Zheng et al., 2011). This modification of the temporal firing pattern can result in desynchronization of the firing of STN neurons (Degos et al., 2005). Similar modulation has been demonstrated in the globus pallidus (GP); during HFS of the GP in MPTPtreated primates the majority of neurons in the GP exhibited complex locking to the stimuli, with a stereotypic temporal structure (Bar-Gad et al., 2004). The temporal firing pattern of the GP is also modulated by HFS of the STN (Hashimoto et al., 2003). This reshaping of temporal dynamics may affect information transmission. Degos et al. (2005) and Zheng et al. (2011) found that HFS of the STN decreased, but did not completely interrupt, transmission of information through the STN and regions of the basal ganglia. Thus, HFS may partially uncouple the targeted site from upstream and downstream regions while not significantly altering the intrinsic activity of the site. Debate remains concerning the primary mechanism of this uncoupling; some researchers have implicated synaptic inhibition (Deniau et al., 2010), while others have postulated axonal failure (Zheng et al., 2011).

\section{NEUROGENESIS AND PLASTICITY}

In contrast to DBS for PD, the therapeutic effect of DBS for OCD takes weeks to months to manifest, which raises the possibility of additional mechanisms beyond acute alteration firing rates and patterns. Similar to recent findings with the use of SSRI (Malberg et al., 2000; Santarelli et al., 2003), a common treatment for OCD, DBS may induce hippocampal neurogenesis. Multiple studies have demonstrated proliferation and/or survival of dentate gyrus cells (DGCs) in vivo following tetanic stimulation of mossy fibers, the entorhinal cortex, or perforant path in rodents (Derrick et al., 2000; Bruel-Jungerman et al., 2006; Chun et al., 2006; Kitamura et al., 2010; Stone et al., 2011). Behavioral correlates, involving enhancement of memory and learning, have also been demonstrated following stimulation, depending on the time lapse between stimulation and testing. Hamani and colleagues administered HFS to the anterior thalamic nucleus (ATN) of corticosterone treated rats, which is known to reduce neurogenesis and diminish learning and memory performance (Hamani et al., 2011). Thirty-three days later, the stimulated rodents performed significantly better on a common memory test, a delayed nonmatching to sample task, as compared to their unstimulated, corticosterone treated counterparts. This behavioral enhancement was not evident prior to 33 days, suggestive of long-term plastic changes. Time may also explain a discrepancy in the literature, in which ATN HFS was shown to impair rodents' contextual fear conditioning (Hamani et al., 2010); the researchers did not wait as long to test the rodents as in their subsequent study (Hamani et al., 2011). Stone and colleagues (2011) also reported enhancement of mouse spatial memory at 6 weeks, but not 1 week, following bilateral entorhinal cortex stimulation. Corresponding to these time points, integration of DGCs into dentate circuits was observed at 6 weeks but not 1 week following stimulation.
When the DNA alkylating agent temozolomide (TMZ) was used to obstruct adult neurogenesis, the previous improvements in spatial memory were not apparent, further substantiating a role of HFS in adult neurogenesis with behavioral effect. Given the abnormalities observed in the hippocampus in imaging studies, hippocampal neurogenesis, and in turn, HFS, may have an ameliorating effect among such patients.

\section{VARIABILITY OF THE LOCAL EFFECT OF HFS}

As shown by the studies described above, a variety of findings have emerged in the study of mechanisms of DBS. While several studies have demonstrated partial failure of axonal conduction with low fidelity to the frequency of stimulation (Urbano et al., 2002; Zheng et al., 2011), others have reported driving of neurons at the same frequency as stimulation (Garcia et al., 2003; Hashimoto et al., 2003; Li et al., 2007). Differences between in vivo and in vitro preparations, brain regions, species, and normal and diseased tissue may affect the proportion of blocked to transmitted action potentials and contribute to this discrepancy (Zheng et al., 2011). Variations between regions in neural and glial cell types as well as the proportion of local cells versus fibers of passage and afferent inputs may also alter the response of the region to stimulation. For example, some neurons of the STN display a resurgent $\mathrm{Na}+$ current which is modified by HFS (Do and Bean, 2003). In contrast, a similar current has never been demonstrated in the thalamus, which may explain contrasting results from studies of HFS of this region (Anderson et al., 2004). Glia, which vary among regions, may also have a pronounced influence on the effect of HFS: Tawfik and colleagues (2010) demonstrated that HFS of the thalamus causes release of glutamate from astrocytes, concurrent with an abolition of spindle activity in the thalamocortical network. Even within a given region, multiple neural response types are often identified (Maurice et al., 2003; Tai et al., 2003; Deniau et al., 2010; Zheng et al., 2011); such variability may render the results of HFS of one region less comparable to another.

Although the mechanisms of DBS still remain unclear, this diversity of findings may indicate that many of these mechanisms occur, with the predominance of their respective effect dependent on disease state and regional factors. Despite the possible specificity of findings to target regions, a general hypothesis may emerge from the debate-DBS suppresses pathological network activity, while allowing normal information transmission to occur.

\section{EFFECT OF DBS ON OCD CIRCUITRY}

While DBS for OCD is a relatively new treatment, several functional imaging and animal studies exist investigating the functional changes underlying the therapeutic effects of DBS. We examine these in the context of the mechanisms of action of DBS in order to better understand how DBS effects therapeutic benefit in OCD.

\section{STN STIMULATION}

STN DBS was initially investigated for OCD because of effects on similar symptoms noted in PD patients. PD patients treated with STN DBS have decreased obsessive compulsive traits (Alegret et al., 2001). Case reports of 3 PD patients treated with STN 
DBS who incidentally had comorbid OCD reported substantial improvement of OCD symptoms with STN stimulation (Mallet et al., 2002; Fontaine et al., 2004). In all three patients the electrode location was more medial than the standard PD target, likely contributing to this effect. Subsequently a clinical trial with patients randomized to actual or sham stimulation in a crossover design showed that OCD patients with STN DBS targeted to the border of the associative and limbic territories of the STN, anteromedial to the standard PD target, showed significant improvement in Y-BOCS scores with stimulation (Mallet et al., 2008). Stimulation related side effects of STN DBS in OCD patients include transient dyskinesia, peripheral vertigo, hypomania, mania, depression, and anxiety (Mallet et al., 2008).

Similar to STN DBS in humans, STN HFS decreases OCD like behavior in animal models, and this modification may occur due to the inhibitory and excitatory mechanisms discussed previously. STN HFS and pharmacologic inactivation in a rat model both decrease OCD like behavior (Winter et al., 2008b; Klavir et al., 2009), suggesting that HFS and lesion act similarly in this paradigm. Anterior STN HFS decreases stereotypic behaviors in primates with stereotypies induced by injection of the GABA antagonist bicuculline into the limbic globus pallidus externus (GPe) (Baup et al., 2008). STN stimulation decreases firing of $\mathrm{SNr}$ and entopeduncular nucleus (EP, a GPi homolog) neurons while increasing activity of GPe neurons (Benazzouz et al., 1995). STN receives efferent connections from GPe and projects to GPi and SNr. GPe projections terminate near STN cells originating connections to GPi and SNr (Joel and Weiner, 1997) thus stimulation may inhibit STN neural firing and output to SNr and GPi while being in a position to retrogradely activate GPe axons. In this way STN stimulation may disrupt the abnormal GPe activity induced by bicuculline injection in the primate model. Anatomic studies of this model have shown that the GPe region that induces stereotypic behaviors when injected with bicuculline receives projections from dorsal NAc/ventral head of the caudate nucleus and projects mostly to $\mathrm{SNr}$ with some projections to GPi (Francois et al., 2004). Thus, it is connected to structures known to be involved in OCD and may modulate activity of circuits involved in OCD or dopaminergic tone, which may be altered in this condition. The predictions of this model may have implications for human pathology and STN DBS for OCD. Modulation of GPi and GPe activity may alter signaling in cortico-basal ganglia circuits involved in OCD. Overall, these findings provide support to the theory that DBS, at least in the STN, inhibits local neurons and their output but causes antidromic activation of efferent projections and via these mechanisms modulates activity of regions of pathologic brain activity in OCD.

Research in rats has shown altered neurotransmitter concentrations in a number of structures with STN stimulation. Striatal dopamine increases with STN stimulation in rats (Bruet et al., 2001; Lee et al., 2006). STN stimulation caused a nonsignificant trend toward increased dopamine in the NAc core and a significant increase of dopamine in the NAc shell as well as decreased GABA in the ventral tegmental area (VTA) (Winter et al., 2008a). In this study VTA lesions prevented STN stimulation induced modulation of NAc dopamine levels suggesting that STN stimulation acts via activation of VTA dopaminergic neurons to increase dopamine in the NAc. Dopaminergic signaling in the NAc is involved in motivation and reward; STN DBS induced alteration of NAc dopamine levels may combat abnormal reward processing in OCD.

Several functional imaging studies provide insight into altered metabolism induced by STN DBS (Table 2). In two PD patients, stimulation of electrode contacts near the border of the associative and limbic regions of the STN, a location similar to that used in OCD, induced a hypomanic state; stimulation of these contacts decreased medial prefrontal cortex (mPFC)/anterior cingulate gyrus and increased left thalamus activation imaged with PET (Mallet et al., 2007). OCD patients treated with STN DBS had decreased metabolism in the anterior cingulate gyrus and medial gyrus of the left frontal lobe during PET imaging, with decrease in Y-BOCS scores correlating with decreases in OFC and mPFC metabolism (Le Jeune et al., 2010). STN DBS may modulate reciprocal direct connections that exist between the STN and PFC (Degos et al., 2008), thereby causing the observed alterations in prefrontal activity (Le Jeune et al., 2010). An alternative explanation is that STN stimulation alters activity of subcortical components of the CSTC circuit, perhaps by altering activity of the GP, one of the primary basal ganglia output structures, as discussed above. Ultimately it appears that STN stimulation decreases ACC activity and that therapeutic effects are additionally related to decreased OFC metabolism. Interestingly, PET studies have shown decreased metabolism in these two areas with pharmacologic therapy (Swedo et al., 1992; Perani et al., 1995) and cingulotomy can be an effective treatment for patients refractory to pharmacologic and behavioral therapy. These findings suggest that altered activity of OFC and ACC is a key part of the dysfunctional circuitry of OCD and that modulation of this abnormal activity is common to the mechanism of action of behavioral, pharmacologic, and surgical therapy.

\section{ANTERIOR LIMB OF THE INTERNAL CAPSULE AND VENTRAL STRIATUM STIMULATION}

A number of case reports have documented benefit of stimulation of ALIC or a more ventral target in the ventral ALIC and ventral striatum which includes the NAc and is termed ventral capsule/ventral striatum (VC/VS) (Anderson and Ahmed, 2003; Gabriels et al., 2003; Franzini et al., 2010). This benefit seems to persist even with blinding to stimulation state (Nuttin et al., 1999). Larger trials using randomized, blinded assignment to stimulation versus sham stimulation have strengthened evidence of benefit of DBS in these regions (Nuttin et al., 2003; Abelson et al., 2005; Denys et al., 2010; Goodman et al., 2010), with a study of VC/VS stimulation showing significant sustained improvement in Y-BOCS scores at three years following surgery (Greenberg et al., 2006). Unilateral ALIC/NAc DBS has also been studied and shown to have some effect (Sturm et al., 2003; Huff et al., 2010). Finally, case reports of stimulation of the ventral caudate in addition to the NAc have shown significant decrease in Y-BOCS scores (Aouizerate et al., 2004, 2009). Several side effects have been reported with ALIC and VC/VS stimulation. Several reports have described unilateral cheek muscle contraction with acute ALIC stimulation, corresponding with increased mood (Baker et al., 2007). Paresthesias and nausea have been associated with 
Table 2 | Findings of functional imaging studies during stimulation of DBS targets used for OCD.

\begin{tabular}{|c|c|c|c|}
\hline & STN DBS & ALIC DBS & VC/VS DBS \\
\hline Medial PFC & $\downarrow$ Mallet et al., 2007 & - & - \\
\hline DLPFC & - & $\begin{array}{l}\uparrow \downarrow \text { Baker et al., 2007; Van Laere et al., } \\
2006\end{array}$ & - \\
\hline ACC & $\begin{array}{l}\downarrow \text { Mallet et al., 2007; Le Jeune et al., } \\
2010\end{array}$ & $\begin{array}{l}\uparrow \downarrow \text { Baker et al., 2007; Van Laere et al., } \\
2006\end{array}$ & $\uparrow$ Baker et al., 2007 \\
\hline Medial frontal gyrus & $\downarrow$ Le Jeune et al., 2010 & - & - \\
\hline Superior frontal gyrus & - & - & $\uparrow$ Baker et al., 2007 \\
\hline Middle frontal gyrus & $\uparrow$ Baker et al., 2007 & - & $\uparrow$ Baker et al., 2007 \\
\hline Inferior frontal gyrus & $\uparrow$ Mallet et al., 2007 & - & $\uparrow$ Baker et al., 2007 \\
\hline Frontal cortex & - & $\uparrow \downarrow$ Nuttin et al., 2003 & - \\
\hline Middle temporal gyrus & $\uparrow \downarrow$ Mallet et al., 2007 & $\uparrow$ Nuttin et al., 2003 & - \\
\hline Inferior temporal gyrus & $\uparrow$ Mallet et al., 2007 & - & - \\
\hline Middle occipital gyrus & $\downarrow$ Mallet et al., 2007 & - & - \\
\hline Lateral occipital cortex & - & $\uparrow$ Nuttin et al., 2003 & - \\
\hline Bilateral cuneus & $\downarrow$ Mallet et al., 2007 & - & - \\
\hline Striatum & - & $\begin{array}{l}\uparrow \downarrow \text { Nuttin et al., 2003; Van Laere et al., } \\
2006\end{array}$ & - \\
\hline Caudate & - & 个 Baker et al., 2007 & $\uparrow$ Baker et al., 2007 \\
\hline Globus pallidus & - & $\uparrow$ Baker et al., 2007 & $\uparrow$ Rauch et al., 2006 \\
\hline Putamen & - & 个 Baker et al., 2007 & $\begin{array}{l}\uparrow \text { Baker et al., 2007; Rauch } \\
\text { et al., } 2006\end{array}$ \\
\hline
\end{tabular}

Arrows indicate direction of change in activity with stimulation of the indicated target.

higher voltage stimulation, perhaps especially with stimulation of ventral contacts 0 and 1 (Abelson et al., 2005; Baker et al., 2007). Fatigue lasting for several months and weight changes, both loss and gain, have been noted (Nuttin et al., 2003). Elevated mood, hyperactivity, dysinhibition, increased talkativeness, irritability, and decreased need for sleep, sometimes reaching the level of mania or hypomania may occur with ALIC stimulation, especially at higher stimulation voltages and with stimulation of ventral contacts (Gabriels et al., 2003; Nuttin et al., 2003; Abelson et al., 2005; Chang et al., 2009, 2010). VC/VS stimulation may also induce impulsive behavior, hypomania or mania (Denys et al., 2010; Goodman et al., 2010; Greenberg et al., 2010a; Haq et al., 2010; Tsai et al., 2010; Luigjes et al., 2011). Similarly to ALIC stimulation, unilateral smile is common with VC/VS acute stimulation (Greenberg et al., 2006, 2010a; Goodman et al., 2010). Some patients experience transient stomachaches or nausea with VC/VS stimulation (Okun et al., 2007; Denys et al., 2010). Other reported side effects include headaches, cold shivers, difficulty falling asleep, and paresthesias (Okun et al., 2007; Denys et al., 2010; Greenberg et al., 2010a; Huff et al., 2010). Some patients 
report cognitive effects such as forgetfulness, word finding difficulties, verbal perseveration, cognitive clouding, or decreased concentration (Okun et al., 2007; Denys et al., 2010; Greenberg et al., 2010a; Huff et al., 2010). VC/VS stimulation can cause acute emotional changes such as euphoria, sadness, or anxiety occasionally reaching the level of panic attack (Greenberg et al., 2006, 2010a; Goodman et al., 2010; Huff et al., 2010). Panic and anxiety may be associated with autonomic changes and occur more frequently with stimulation of ventral contacts (Shapira et al., 2006; Okun et al., 2007; Goodman et al., 2010). Changes in taste, either decreased taste sensation or transient olfactory and gustatory sensations may occur with VC/VS stimulation, especially with ventral contact stimulation (Greenberg et al., 2006, 2010a; Okun et al., 2007; Denys et al., 2010; Goodman et al., 2010). Overall, stimulation induced adverse events are more likely to occur with stimulation of ventral contacts (Greenberg et al., 2006). Transient hypomania is the most common side effect experienced immediately after stimulation is begun and is more common with VC/VS than STN stimulation (de Koning et al., 2011). In general, stimulation induced adverse effects are almost always transient and remit with alteration of stimulation settings.

Stimulation of the NAc core and shell may have different effects. Studies in rats have demonstrated decreased impulsivity and perseverative behavior with NAc core stimulation but increased impulsivity and decreased perseverative behavior with NAc shell stimulation (Sesia et al., 2008, 2010). In contrast, NAc core lesions increase impulsivity while shell lesions do not (Pothuizen et al., 2005). NAc lesions have been reported to destroy the ability to hold reward value over time in a delayed reward task, resulting in impulsive behavior (Cardinal et al., 2001). This suggests that the effect of NAc stimulation is more complex than inhibition. The increase in impulsivity with NAc shell stimulation may be related to changes in local neurotransmitter concentrations: NAc shell HFS also increased concentrations of NAc dopamine and serotonin (Sesia et al., 2010), while NAc core stimulation does not in result in any local change in dopamine, serotonin, or noradrenaline concentrations (van Dijk et al., 2011). In human subjects NAc stimulation occasionally results in disinhibition, impulsiveness, or mania with increasing stimulation voltage (Haq et al., 2010; Luigjes et al., 2011) similarly to NAc lesion these effects may result from local inhibition and dysfunctional reward processing leading to impulsivity. Given the work by Sesia and colleagues it is possible that impulsivity is related to the effect of DBS on the NAc shell; alternatively stimulation could be causing an inhibitory effect analogous to a core lesion. The NAc core and shell have different inputs and projections, likely contributing to the observed differences between core and shell stimulation. The shell has reciprocal projections with VTA that may contribute to changes in dopamine concentrations with stimulation. STN stimulation also results in increased NAc dopamine concentrations, suggesting that NAc dopamine may be important for the observed therapeutic effects of DBS in OCD. However, increased NAc dopamine may also contribute to dysfunctional reward signaling and increased impulsivity which can be seen as a side effect of both STN and NAc stimulation.

HFS and low frequency stimulation (LFS) of the NAc have different effects on neural firing rates and patterns. NAc core
HFS but not LFS increases slow local field potential (LFP) oscillations in OFC and decreases firing of OFC neurons, likely via antidromic activation of corticostriatal projections, activating inhibitory interneurons (McCracken and Grace, 2007). Low frequency NAc stimulation resulted in increased theta activity in MD thalamus and NAc, while HFS increased beta power in OFC and MD thalamus and gamma power in OFC, mPFC, and MD thalamus. HFS additionally increased beta coherence between MD thalamus and OFC, $\mathrm{mPFC}$, and NAC and gamma coherence between OFC-PFC and OFC-MD thalamus while LFS decreased OFCPFC and OFC-MD thalamus gamma coherence (McCracken and Grace, 2009). Because fast oscillations are generated by synchronization in inhibitory interneuron networks (Traub et al., 2004), the authors postulate that NAc HFS may generate therapeutic effects via synchronization of inhibition in dysfunctional OCD circuits. As discussed above, in untreated OCD patients correlation between OFC and ipsilateral thalamus and caudate activity measured with PET has been reported with disappearance of this correlation following treatment (Baxter et al., 1992; Schwartz et al., 1996); perhaps NAc DBS synchronizes inhibition of these pathologically hyperactive circuits. Interestingly, OCD patients have increased EEG theta power especially in frontal temporal and frontal occipital regions (Desarkar et al., 2007) and decreased beta power (Kuskowski et al., 1993), which one study reported localized to frontal regions (Serra et al., 1994). Thus, the therapeutic effects of NAc DBS may be related to the reversal of these abnormal oscillations.

Behavioral studies also support the different effects of NAc HFS and LFS. Stimulation of the NAc core or shell decreases compulsive behavior in rats (Mundt et al., 2009), however this effect is seen only with HFS and not with LFS (van Kuyck et al., 2008). In fact, increased compulsive behavior was observed in a rat repetitive and compulsive behavior model with NAc LFS or lesion (van Kuyck et al., 2003). The opposite effects of HFS and LFS on synchronization may be related to the increased compulsive behavior with LFS seen in this study. The similar behavioral effects of LFS and lesion in this study suggest that LFS of the NAc may have some inhibitory characteristics. The lesion like effects of both HFS and LFS in different behavioral experiments despite clear behavioral and neurophysiological effects of HFS and LFS when studied together demonstrate that the mechanism of DBS is more complicated than simple inhibition. Frequency modulation of antidromic and orthodromic axonal conduction and different effects on cell bodies and axons likely contribute to these complexities.

DBS in the region of the ALIC and the ventral striatum in OCD patients alters activity in structures known to be involved in OCD, particularly OFC and ACC (Table 2). In one PET study ALIC DBS decreased OFC metabolism in two patients who benefited from stimulation but did not alter OFC metabolism in a third patient who experienced no benefit from DBS (Abelson et al., 2005), suggesting that modulation of OFC activity is important to the therapeutic effect of ALIC DBS. Frontal metabolism was decreased and striatal activity increased with ALIC DBS in two patients who underwent PET in one study (Nuttin et al., 2003). While studies of OCD patients generally indicate increased activity in areas such as OFC, caudate and ACC with decreased 
activity following successful treatment, discrepancies in findings suggest that OCD pathophysiology and therapeutic mechanisms are likely more complicated than simple increases and decreases in activity. Contrary to the findings of Nuttin and colleagues, Van Laere et al. used PET to find preoperative decreased metabolism in ventral PFC and dorsal anterior cingulate and increased metabolism in ventral striatum in a group of six OCD patients (Van Laere et al., 2006). Following several months of ALIC stimulation these patients demonstrated decreased metabolism in subgenual ACC and right DLPFC, with normalization of ventral striatum metabolism. Additionally, decrease in ventral striatum metabolism correlated with decrease in Y-BOCS scores while increased preoperative subgenual ACC activity was predictive of positive response to stimulation. Thus, ALIC DBS likely acts by modulating abnormal activity in circuits involving OFC, ACC, and striatum.

ALIC and VC/VS stimulation induce changes in activity in similar brain regions. In a case report of one patient with a VC/VS electrode studied with fMRI, stimulation of a contact located in the ALIC resulted in activation in the middle frontal gyrus, MD thalamus, ACC, head of the caudate nucleus, and GP. Stimulation of the ventral most contact in the same patient, located in the ventral striatum, also resulted in activation of MD thalamus and head of the caudate nucleus as well as posterior cingulate cortex and superior, middle, and inferior frontal gyrus (Baker et al., 2007). In a group of six patients with therapeutic benefit from VC/VS stimulation PET showed increased blood flow in mOFC, subgenual ACC, putamen, GP, and thalamus with stimulation (Rauch et al., 2006), although this study took place soon after electrode implantation and before subjects had been exposed to chronic stimulation which may alter the findings, especially considering the often delayed therapeutic effects of DBS for OCD. Overall, both VC/VS and ALIC stimulation seem to cause changes in activity in regions involved in OCD, including OFC, ACC, striatum, and thalamus. While the direction of change is not always consistent, this may reflect a modulation rather than inhibition of abnormal activity in these areas. One possible mechanism for changes observed with VC/VS stimulation is antidromic activation of corticostriatal fibers modulating

\section{REFERENCES}

Abelson, J. L., Curtis, G. C., Sagher, O., Albucher, R. C., Harrigan, M., Taylor, S. F., Martis, B., and Giordani, B. (2005). Deep brain stimulation for refractory obsessive-compulsive disorder. Biol. Psychiatry 57, 510-516.

Adler, C. M., McDonough-Ryan, P., Sax, K. W., Holland, S. K., Arndt, S., and Strakowski, S. M. (2000). fMRI of neuronal activation with symptom provocation in unmedicated patients with obsessive compulsive disorder. J. Psychiatr. Res. 34, 317-324.

Aggleton, J. P. (1993). The contribution of the amygdala to normal and abnormal emotional states. Trends Neurosci. 16, 328-333.
Alegret, M., Junque, C., Valldeoriola, F., Vendrell, P., Pilleri, M., Rumia, J., and Tolosa, E. (2001). Effects of bilateral subthalamic stimulation on cognitive function in Parkinson disease. Arch. Neurol. 58, 1223-1227.

Anderson, D., and Ahmed, A. (2003). Treatment of patients with intractable obsessive-compulsive disorder with anterior capsular stimulation. Case report. J. Neurosurg. 98, 1104-1108.

Anderson, M. E., Postupna, N., and Ruffo, M. (2003). Effects of highfrequency stimulation in the internal globus pallidus on the activity of thalamic neurons in the awake monkey. J. Neurophysiol. 89, 1150-1160.

CSTC circuits. OFC and ACC have bidirectional connections with thalamus passing in the region of VC/VS, thus stimulation may orthodromically and antidromically stimulate these tracts to modulate OFC, ACC, and thalamic activity (Rauch et al., 2006). ALIC stimulation may affect projections from OFC/subgenual ACC to thalamus running in the internal capsule or frontostriatal projections. Capsulotomy is thought to act by disrupting reciprocal projections between the OFC and MD thalamic nucleus that travel through the internal capsule; ALIC stimulation may act in a similar way. It has been hypothesized that the dysfunctional circuitry of OCD involves pathological positive feedback in these OFC-thalamic connections (Modell et al., 1989). DBS may act to dampen this hyperactivity and disrupt pathological signaling. Finally, as well as modulating activity in the structures and circuits targeted, DBS may affect neighboring structures and tracts. Relative location of DBS leads to particular fiber tracts may result in differential modulation of separate cortical subcortical circuits (Greenberg et al., 2010b). This may have an important impact on differing clinical effects of DBS for OCD and may explain some of the discrepancies in functional imaging findings.

\section{CONCLUSION}

Accumulating evidence suggests that DBS is an effective therapy for treatment resistant OCD. Despite its efficacy, its mechanism remains poorly understood. As this treatment gains increasing acceptance and use more extensive studies in human and animal subjects may help to elucidate how DBS alters and remedies OCD pathology. DBS appears to alter activity in a number of regions with abnormal activity in OCD including OFC, ACC, and striatum, providing further evidence for the involvement of these regions in OCD pathology. Multiple effects of DBS on neural activity have been reported. DBS inhibits local neural firing while activating antidromic and orthodromic axonal conduction. It alters concentrations of excitatory and inhibitory neurotransmitters. It alters neural firing patterns, information transmission, and coherence between different regions. It may even affect neurogenesis. Ultimately, the mechanism of action behind the therapeutic effects of DBS in OCD is likely comprised of a complex combination of these effects.

Anderson, T., Hu, B., Pittman, Q., and Kiss, Z. H. (2004). Mechanisms of deep brain stimulation: an intracellular study in rat thalamus. $J$. Physiol. 559, 301-313.

Aouizerate, B., Cuny, E., Bardinet, E., Yelnik, J., Martin-Guehl, C., Rotge, J. Y., Rougier, A., Bioulac, B., Tignol, J., Mallet, L., Burbaud, P., and Guehl, D. (2009). Distinct striatal targets in treating obsessivecompulsive disorder and major depression. J. Neurosurg. 111, 775-779.

Aouizerate, B., Cuny, E., MartinGuehl, C., Guehl, D., Amieva, H., Benazzouz, A., Fabrigoule, C., Allard, M., Rougier, A., Bioulac, B., Tignol, J., and Burbaud, P. (2004). Deep brain stimulation of the ventral caudate nucleus in the treatment of obsessive-compulsive disorder and major depression. Case report. J. Neurosurg. 101, 682-686.

Atmaca, M. (2011). Review of structural neuroimaging in patients with refractory obsessive-compulsive disorder. Neurosci. Bull. 27, 215-220.

Atmaca, M., Yildirim, H., Ozdemir, H., Koc, M., Ozler, S., and Tezcan, E. (2009). Neurochemistry of the hippocampus in patients with obsessive-compulsive disorder. Psychiatry Clin. Neurosci. 63, 486-490.

Atmaca, M., Yildirim, H., Ozdemir, H., Ozler, S., Kara, B., Ozler, Z., Kanmaz, E., Mermi, O., and Tezcan, E. (2008). Hippocampus and 
amygdalar volumes in patients with refractory obsessive-compulsive disorder. Prog. Neuropsychopharmacol. Biol. Psychiatry 32, 1283-1286.

Baker, K. B., Kopell, B. H., Malone, D., Horenstein, C., Lowe, M., Phillips, M. D., and Rezai, A. R. (2007). Deep brain stimulation for obsessivecompulsive disorder: using functional magnetic resonance imaging and electrophysiological techniques: technical case report. Neurosurgery 61, E367-E368. discussion E368.

Baldissera, F., Lundberg, A., and Udo, M. (1972). Stimulation of preand postsynaptic elements in the red nucleus. Exp. Brain Res. 15, 151-167.

Bar-Gad, I., Elias, S., Vaadia, E., and Bergman, H. (2004). Complex locking rather than complete cessation of neuronal activity in the globus pallidus of a 1-methyl-4-phenyl1,2,3,6-tetrahydropyridine-treated primate in response to pallidal microstimulation. J. Neurosci. 24, 7410-7419.

Bartha, R., Stein, M. B., Williamson, P. C., Drost, D. J., Neufeld, R. W., Carr, T. J., Canaran, G., Densmore, M., Anderson, G., and Siddiqui, A. R. (1998). A short echo $1 \mathrm{H}$ spectroscopy and volumetric MRI study of the corpus striatum in patients with obsessive-compulsive disorder and comparison subjects. Am. J. Psychiatry 155, 1584-1591.

Baup, N., Grabli, D., Karachi, C., Mounayar, S., Francois, C., Yelnik, J., Feger, J., and Tremblay, L. (2008). High-frequency stimulation of the anterior subthalamic nucleus reduces stereotyped behaviors in primates. J. Neurosci. 28, 8785-8788.

Baxter, L. R. Jr., Phelps, M. E., Mazziotta, J. C., Guze, B. H., Schwartz, J. M., and Selin, C. E. (1987). Local cerebral glucose metabolic rates in obsessivecompulsive disorder. A comparison with rates in unipolar depression and in normal controls. Arch. Gen. Psychiatry 44, 211-218.

Baxter, L. R., Schwartz, J. M., Bergman, K. S., Szuba, M. P., Guze, B. H., Mazziotta, J. C., Alaz- raki, A., Selin, C. E., Ferng, H. K., Munford, P., and Phelps, M. E. (1992). Caudate glucose metabolic rate changes with both drug and behavior therapy for obsessive-compulsive disorder. Arch. Gen. Psychiatry 49, 681-689.

Baxter, L. R. Jr., Schwartz, J. M., Mazziotta, J. C., Phelps, M. E., Pahl, J. J., Guze, B. H., and Fairbanks, L. (1988). Cerebral glucose metabolic rates in nondepressed patients with obsessive-compulsive disorder. Am. J. Psychiatry 145, 1560-1563.

Bekar, L., Libionka, W., Tian, G. F., Xu, Q., Torres, A., Wang, X. Lovatt, D., Williams, E., Takano, T., Schnermann, J., Bakos, R., and Nedergaard, M. (2008). Adenosine is crucial for deep brain stimulation-mediated attenuation of tremor. Nat. Med. 14, 75-80.

Bellinger, S. C., Miyazawa, G., and Steinmetz, P. N. (2008). Submyelin potassium accumulation may functionally block subsets of local axons during deep brain stimulation: a modeling study. J. Neural Eng. 5, 263-274.

Benazzouz, A., and Hallett, M. (2000). Mechanism of action of deep brain stimulation. Neurology 55, S13-S16.

Benazzouz, A., Piallat, B., Pollak, P., and Benabid, A. L. (1995). Responses of substantia nigra pars reticulata and globus pallidus complex to high frequency stimulation of the subthalamic nucleus in rats: electrophysiological data. Neurosci. Lett. 189 , 77-80.

Benkelfat, C., Nordahl, T. E., Semple, W. E., King, A. C., Murphy, D. L., and Cohen, R. M. (1990). Local cerebral glucose metabolic rates in obsessive-compulsive disorder. Patients treated with clomipramine. Arch. Gen. Psychiatry 47, 840-848.

Besiroglu, L., Sozen, M., Ozbebit, O., Avcu, S., Selvi, Y., Bora, A., Atli, A., Unal, O., and Bulut, M. D. (2011). The involvement of distinct neural systems in patients with obsessivecompulsive disorder with autogenous and reactive obsessions. Acta Psychiatr. Scand. 124, 141-151.

Beurrier, C., Bioulac, B., Audin, J., and Hammond, C. (2001). Highfrequency stimulation produces a transient blockade of voltage-gated currents in subthalamic neurons. J. Neurophysiol. 85, 1351-1356.

Bikson, M., Lian, J., Hahn, P. J., Stacey, W. C., Sciortino, C., and Durand, D. M. (2001). Suppression of epileptiform activity by high frequency sinusoidal fields in rat hippocampal slices. J. Physiol. 531, 181-191.

Boraud, T., Bezard, E., Bioulac, B., and Gross, C. (1996). High frequency stimulation of the internal Globus Pallidus (GPi) simultaneously improves parkinsonian symptoms and reduces the firing frequency of GPi neurons in the MPTP-treated monkey. Neurosci. Lett. 215, 17-20.

Bouton, M. E., and Bolles, R. C. (1979). Role of conditioned contextual stimuli in reinstatement of extinguished fear. J. Exp. Psychol. Anim. Behav. Process. 5, 368-378.

Bouton, M. E., and King, D. A. (1983). Contextual control of the extinction of conditioned fear: tests for the associative value of the context. $J$. Exp. Psychol. Anim. Behav. Process. 9, 248-265.

Breiter, H. C., Rauch, S. L., Kwong, K. K., Baker, J. R., Weisskoff, R. M., Kennedy, D. N., Kendrick, A. D., Davis, T. L., Jiang, A., Cohen, M. S., Stern, C. E., Belliveau, J. W., Baer, L., O'Sullivan, R. L., Savage, C. R., Jenike, M. A., and Rosen, B. R. (1996). Functional magnetic resonance imaging of symptom provocation in obsessive-compulsive disorder. Arch. Gen. Psychiatry 53, 595-606.

Bruel-Jungerman, E., Davis, S., Rampon, C., and Laroche, S. (2006). Long-term potentiation enhances neurogenesis in the adult dentate gyrus. J. Neurosci. 26, 5888-5893.

Bruet, N., Windels, F., Bertrand, A., Feuerstein, C., Poupard, A., and Savasta, M. (2001). High frequency stimulation of the subthalamic nucleus increases the extracellular contents of striatal dopamine in normal and partially dopaminergic denervated rats. J. Neuropathol. Exp. Neurol. 60, 15-24.

Burbaud, P., Gross, C., and Bioulac, B. (1994). Effect of subthalamic high frequency stimulation on substantia nigra pars reticulata and globus pallidus neurons in normal rats. J. Physiol. Paris 88, 359-361.

Busatto, G. F., Zamignani, D. R., Buchpiguel, C. A., Garrido, G. E. Glabus, M. F., Rocha, E. T., Maia, A F., Rosario-Campos, M. C., Campi Castro, C., Furuie, S. S., Gutierrez, M. A., McGuire, P. K., and Miguel, E. C. (2000). A voxel-based investigation of regional cerebral blood flow abnormalities in obsessivecompulsive disorder using single photon emission computed tomography (SPECT). Psychiatry Res. 99, 15-27.

Cahill, L., and McGaugh, J. L. (1998). Mechanisms of emotional arousal and lasting declarative memory. Trends Neurosci. 21, 294-299.

Cardinal, R. N., Pennicott, D. R., Sugathapala, C. L., Robbins, T. W., and Everitt, B. J. (2001). Impulsive choice induced in rats by lesions of the nucleus accumbens core. Science 292, 2499-2501.

Carlson, J. D., Cleary, D. R., Cetas, J. S., Heinricher, M. M., and Burchiel, K. J. (2010). Deep brain stimulation does not silence neurons in subthalamic nucleus in Parkinson's patients. J. Neurophysiol. 103, 962-967.

Chang, C. H., Chen, S. Y., Hsiao, Y. L., Chen, S. J., Tsai, S. T., Yeh, Y. Y., and Tsai, H. C. (2009). Hypomanialike syndrome induced by deep brain stimulation of bilateral anterior limbs of the internal capsules. Prog. Neuropsychopharmacol. Biol. Psychiatry 33, 906-907.

Chang, C. H., Chen, S. Y., Hsiao, Y. L., Tsai, S. T., and Tsai, H. C. (2010). Hypomania with hypersexuality following bilateral anterior limb stimulation in obsessive-compulsive disorder. J. Neurosurg. 112, 1299-1300.

Chun, S. K., Sun, W., Park, J. J., and Jung, M. W. (2006). Enhanced proliferation of progenitor cells following long-term potentiation induction in the rat dentate gyrus. Neurobiol. Learn. Mem. 86, 322-329.

Cottraux, J., Gerard, D., Cinotti, L., Froment, J. C., Deiber, M. P., Le Bars, D., Galy, G., Millet, P., Labbe, C., Lavenne, F., Bouvard, M. and Mauguiere, F. (1996). A controlled positron emission tomography study of obsessive and neutral auditory stimulation in obsessivecompulsive disorder with checking rituals. Psychiatry Res. 60, 101-112.

de Koning, P. P., Figee, M., Van Den Munckhof, P., Schuurman, P. R., and Denys, D. (2011). Current status of deep brain stimulation for obsessive-compulsive disorder: a clinical review of different targets. Curr. Psychiatry Rep. 13, 274-282.

Degos, B., Deniau, J. M., Le Cam, J., Mailly, P., and Maurice, N. (2008). Evidence for a direct subthalamocortical loop circuit in the rat. Eur. J. Neurosci. 27, 2599-2610.

Degos, B., Deniau, J. M., Thierry, A. M., Glowinski, J., Pezard, L., and Maurice, N. (2005). Neuroleptic-induced catalepsy: electrophysiological mechanisms of functional recovery induced by high-frequency stimulation of the subthalamic nucleus. J. Neurosci. 25, 7687-7696.

Del Casale, A., Kotzalidis, G. D., Rapinesi, C., Serata, D., Ambrosi, E., Simonetti, A., Pompili, M., Ferracuti, S., Tatarelli, R., and Girardi, P. (2011). Functional neuroimaging in obsessive-compulsive disorder. Neuropsychobiology 64 61-85.

den Braber, A., Van 'T Ent, D., Cath, D. C., Wagner, J., Boomsma, D. I., and De Geus, E. J. (2010). Brain activation during cognitive planning in twins discordant or concordant for obsessive-compulsive symptoms. Brain 133, 3123-3140. 
Deniau, J. M., Degos, B., Bosch, C., and Maurice, N. (2010). Deep brain stimulation mechanisms: beyond the concept of local functional inhibition. Eur. J. Neurosci. 32, 1080-1091.

Denys, D., Mantione, M., Figee, M., Van Den Munckhof, P., Koerselman, F., Westenberg, H., Bosch, A., and Schuurman, R. (2010). Deep brain stimulation of the nucleus accumbens for treatment-refractory obsessivecompulsive disorder. Arch. Gen. Psychiatry 67, 1061-1068.

Denys, D., Van Der Wee, N., Janssen, J., De Geus, F., and Westenberg, H. G. (2004). Low level of dopaminergic D2 receptor binding in obsessive-compulsive disorder. Biol. Psychiatry 55, 1041-1045.

Derrick, B. E., York, A. D., and Martinez, J. L. Jr. (2000). Increased granule cell neurogenesis in the adult dentate gyrus following mossy fiber stimulation sufficient to induce long-term potentiation. Brain Res. 857, 300-307.

Desarkar, P., Sinha, V. K., Jagadheesan, K., and Nizamie, S. H. (2007). Subcortical functioning in obsessive-compulsive disorder: an exploratory EEG coherence study. World J. Biol. Psychiatry 8, 196-200.

Do, M. T., and Bean, B. P. (2003). Subthreshold sodium currents and pacemaking of subthalamic neurons: modulation by slow inactivation. Neuron 39, 109-120.

Dostrovsky, J., Wu, J. P., Levy, R., Hutchison, W. D., Davis, K. D., Tasker, R. R., and Lozano, A. M. (1999). Microstimulation-induced effects on neurons in human globus pallidus and motor thalamus. Soc. Neurosci. Abstr. 375.

Dostrovsky, J. O., Levy, R., Wu, J. P., Hutchison, W. D., Tasker, R. R., and Lozano, A. M. (2000). Microstimulation-induced inhibition of neuronal firing in human globus pallidus. J. Neurophysiol. 84, 570-574.

Dougherty, D. D., Baer, L., Cosgrove, G. R., Cassem, E. H., Price, B. H., Nierenberg, A. A., Jenike, M. A., and Rauch, S. L. (2002). Prospective long-term follow-up of 44 patients who received cingulotomy for treatment-refractory obsessive-compulsive disorder. Am. J. Psychiatry 159, 269-275.

Ebert, D., Speck, O., Konig, A., Berger, M., Hennig, J., and Hohagen, F. (1997). 1H-magnetic resonance spectroscopy in obsessivecompulsive disorder: evidence for neuronal loss in the cingulate gyrus and the right striatum. Psychiatry Res. 74, 173-176.

Fanselow, M. S. (2000). Contextual fear, gestalt memories, and the hippocampus. Behav. Brain Res. 110, 73-81.

Filali, M., Hutchison, W. D., Palter, V. N., Lozano, A. M., and Dostrovsky, J. O. (2004). Stimulation-induced inhibition of neuronal firing in human subthalamic nucleus. Exp. Brain Res. 156, 274-281.

Fitzgerald, K. D., Welsh, R. C., Gehring, W. J., Abelson, J. L., Himle, J. A., Liberzon, I., and Taylor, S. F (2005). Error-related hyperactivity of the anterior cingulate cortex in obsessive-compulsive disorder. Biol. Psychiatry 57, 287-294.

Fontaine, D., Mattei, V., Borg, M., Von Langsdorff, D., Magnie, M. N., Chanalet, S., Robert, P., and Paquis, P. (2004). Effect of subthalamic nucleus stimulation on obsessivecompulsive disorder in a patient with Parkinson disease. Case report. J. Neurosurg. 100, 1084-1086.

Francois, C., Grabli, D., McCairn, K., Jan, C., Karachi, C., Hirsch, E. C., Feger, J., and Tremblay, L. (2004). Behavioural disorders induced by external globus pallidus dysfunction in primates II. Anatomical study. Brain 127, 2055-2070.

Franzini, A., Messina, G., Gambini, O., Muffatti, R., Scarone, S., Cordella, R., and Broggi, G. (2010). Deepbrain stimulation of the nucleus accumbens in obsessive compulsive disorder: clinical, surgical and electrophysiological considerations in two consecutive patients. Neurol. Sci. 31, 353-359.

Gabriels, L., Cosyns, P., Nuttin, B., Demeulemeester, H., and Gybels, J. (2003). Deep brain stimulation for treatment-refractory obsessivecompulsive disorder: psychopathological and neuropsychological outcome in three cases. Acta Psychiatr. Scand. 107, 275-282.

Garcia, L., Audin, J., D’Alessandro, G., Bioulac, B., and Hammond, C. (2003). Dual effect of highfrequency stimulation on subthalamic neuron activity. J. Neurosci. 23, 8743-8751.

Goodman, W. K., Foote, K. D., Greenberg, B. D., Ricciuti, N., Bauer, R., Ward, H., Shapira, N. A., Wu, S. S., Hill, C. L., Rasmussen, S. A., and Okun, M. S. (2010). Deep brain stimulation for intractable obsessive compulsive disorder: pilot study using a blinded, staggeredonset design. Biol. Psychiatry 67, 535-542.

Graybiel, A. M., and Rauch, S. L. (2000). Toward a neurobiology of obsessive-compulsive disorder. Neuron 28, 343-347.

Greenberg, B. D., Gabriels, L. A., Malone, D. A. Jr., Rezai, A. R., Friehs, G. M., Okun, M. S., Shapira, N. A., Foote, K. D., Cosyns, P. R., Kubu, C. S., Malloy, P. F., Salloway, S. P., Giftakis, J. E., Rise, M. T., Machado, A. G., Baker, K. B., Stypulkowski, P. H., Goodman, W. K., Rasmussen, S. A., and Nuttin, B. J. (2010a). Deep brain stimulation of the ventral internal capsule/ventral striatum for obsessive-compulsive disorder: worldwide experience. Mol. Psychiatry 15, 64-79.

Greenberg, B. D., Rauch, S. L., and Haber, S. N. (2010b). Invasive circuitry-based neurotherapeutics: stereotactic ablation and deep brain stimulation for OCD. Neuropsychopharmacology 35, 317-336.

Greenberg, B. D., Malone, D. A., Friehs, G. M., Rezai, A. R., Kubu, C. S., Malloy, P. F., Salloway, S. P., Okun, M. S., Goodman, W. K., and Rasmussen, S. A. (2006). Three-year outcomes in deep brain stimulation for highly resistant obsessive-compulsive disorder. Neuropsychopharmacology 31, 2384-2393.

Grill, W. M., Cantrell, M. B., and Robertson, M. S. (2008). Antidromic propagation of action potentials in branched axons: implications for the mechanisms of action of deep brain stimulation. J. Comput. Neurosci. 24, 81-93.

Gustafsson, B., and Jankowska, E. (1976). Direct and indirect activation of nerve cells by electrical pulses applied extracellularly. $J$. Physiol. 258, 33-61.

Haber, S. N., and Brucker, J. L. (2009). Cognitive and limbic circuits that are affected by deep brain stimulation. Front. Biosci. 14, 1823-1834.

Hamani, C., Nobrega, J. N., and Lozano, A. M. (2010). Deep brain stimulation in clinical practice and in animal models. Clin. Pharmacol. Ther. 88, 559-562.

Hamani, C., Stone, S. S., Garten, A., Lozano, A. M., and Winocur, G. (2011). Memory rescue and enhanced neurogenesis following electrical stimulation of the anterior thalamus in rats treated with corticosterone. Exp. Neurol. 232, 100-104.

Haq, I. U., Foote, K. D., Goodman, W. K., Ricciuti, N., Ward, H., Sudhyadhom, A., Jacobson, C. E., Siddiqui, M. S., and Okun, M. S. (2010). A case of mania following deep brain stimulation for obsessive compulsive disorder.
Stereotact. Funct. Neurosurg. 88, 322-328.

Hashimoto, T., Elder, C. M., Okun, M. S., Patrick, S. K., and Vitek, J. L. (2003). Stimulation of the subthalamic nucleus changes the firing pattern of pallidal neurons. $J$. Neurosci. 23, 1916-1923.

Hong, S. B., Shin, Y. W., Kim, S. H., Yoo, S. Y., Lee, J. M., Kim, I. Y., Kim, S. I., and Kwon, J. S. (2007). Hippocampal shape deformity analysis in obsessive-compulsive disorder. Eur. Arch. Psychiatry Clin. Neurosci. 257, 185-190.

Huff, W., Lenartz, D., Schormann, M., Lee, S. H., Kuhn, J., Koulousakis, A., Mai, J., Daumann, J., Maarouf, M., Klosterkotter, J., and Sturm, V. (2010). Unilateral deep brain stimulation of the nucleus accumbens in patients with treatmentresistant obsessive-compulsive disorder: outcomes after one year. Clin. Neurol. Neurosurg. 112, 137-143.

Iremonger, K. J., Anderson, T. R., Hu, B., and Kiss, Z. H. (2006). Cellular mechanisms preventing sustained activation of cortex during subcortical high-frequency stimulation. $J$. Neurophysiol. 96, 613-621.

Jankowska, E., Padel, Y., and Tanaka, R. (1975). The mode of activation of pyramidal tract cells by intracortical stimuli. J. Physiol. 249, 617-636.

Joel, D., and Weiner, I. (1997). The connections of the primate subthalamic nucleus: indirect pathways and the open-interconnected scheme of basal ganglia-thalamocortical circuitry. Brain Res. Brain Res. Rev. 23, 62-78.

Kessler, R. C., Chiu, W. T., Demler, O., Merikangas, K. R., and Walters, E. E. (2005). Prevalence, severity, and comorbidity of 12-month DSM-IV disorders in the national comorbidity survey replication. Arch. Gen. Psychiatry 62, 617-627.

Kiss, Z. H., Mooney, D. M., Renaud, L., and $\mathrm{Hu}, \mathrm{B}$. (2002). Neuronal response to local electrical stimulation in rat thalamus: physiological implications for mechanisms of deep brain stimulation. Neuroscience 113, 137-143.

Kitamura, T., Saitoh, Y., Murayama, A., Sugiyama, H., and Inokuchi, K. (2010). LTP induction within a narrow critical period of immature stages enhances the survival of newly generated neurons in the adult rat dentate gyrus. Mol. Brain 3,13 .

Klavir, O., Flash, S., Winter, C., and Joel, D. (2009). High frequency stimulation and pharmacological inactivation of the subthalamic 
nucleus reduces 'compulsive' leverpressing in rats. Exp. Neurol. 215, 101-109.

Kringelbach, M. L., and Rolls, E. T. (2004). The functional neuroanatomy of the human orbitofrontal cortex: evidence from neuroimaging and neuropsychology. Prog. Neurobiol. 72, 341-372.

Kuskowski, M. A., Malone, S. M., Kim, S. W., Dysken, M. W., Okaya, A. J., and Christensen, K. J. (1993). Quantitative EEG in obsessive-compulsive disorder. Biol. Psychiatry 33, 423-430.

Kwon, J. S., Shin, Y. W., Kim, C. W., Kim, Y. I., Youn, T., Han, M. H., Chang, K. H., and Kim, J. J. (2003). Similarity and disparity of obsessive-compulsive disorder and schizophrenia in MR volumetric abnormalities of the hippocampus-amygdala complex. J. Neurol. Neurosurg. Psychiatr. 74, 962-964.

Lee, K. H., Blaha, C. D., Harris, B. T., Cooper, S., Hitti, F. L., Leiter, J. C., Roberts, D. W., and Kim, U. (2006). Dopamine efflux in the rat striatum evoked by electrical stimulation of the subthalamic nucleus: potential mechanism of action in Parkinson's disease. Eur. J. Neurosci. 23, 1005-1014.

Lee, K. H., Chang, S. Y., Roberts, D. W., and Kim, U. (2004). Neurotransmitter release from high-frequency stimulation of the subthalamic nucleus. J. Neurosurg. 101, 511-517.

Le Jeune, F., Verin, M., N'Diaye, K., Drapier, D., Leray, E., Du Montcel, S. T., Baup, N., Pelissolo, A., Polosan, M., Mallet, L., Yelnik, J., Devaux, B., Fontaine, D., Chereau, I., Bourguignon, A., Peron, J., Sauleau, P., Raoul, S., Garin, E., Krebs, M. O., Jaafari, N., and Millet, B. (2010). Decrease of prefrontal metabolism after subthalamic stimulation in obsessive-compulsive disorder: a positron emission tomography study. Biol. Psychiatry 68, 1016-1022.

Levy, R., Lang, A. E., Dostrovsky, J. O., Pahapill, P., Romas, J., Saint-Cyr, J., Hutchison, W. D., and Lozano, A. M. (2001). Lidocaine and muscimol microinjections in subthalamic nucleus reverse Parkinsonian symptoms. Brain 124, 2105-2118.

Li, S., Arbuthnott, G. W., Jutras, M. J., Goldberg, J. A., and Jaeger, D. (2007). Resonant antidromic cortical circuit activation as a consequence of high-frequency subthalamic deep-brain stimulation. $J$. Neurophysiol. 98, 3525-3537.
Lian, J., Bikson, M., Sciortino, C., Stacey, W. C., and Durand, D. M. (2003). Local suppression of epileptiform activity by electrical stimulation in rat hippocampus in vitro. $J$. Physiol. 547, 427-434.

Luigjes, J., Mantione, M., Van Den Brink, W., Schuurman, P. R., Van Den Munckhof, P., and Denys, D. (2011). Deep brain stimulation increases impulsivity in two patients with obsessive-compulsive disorder. Int. Clin. Psychopharmacol. 26, 338-340.

Luxenberg, J. S., Swedo, S. E., Flament, M. F., Friedland, R. P., Rapoport, J., and Rapoport, S. I. (1988). Neuroanatomical abnormalities in obsessive-compulsive disorder detected with quantitative X-ray computed tomography. Am. J. Psychiatry 145, 1089-1093.

Machlin, S. R., Harris, G. J., Pearlson, G. D., Hoehn-Saric, R., Jeffery, P., and Camargo, E. E. (1991). Elevated medial-frontal cerebral blood flow in obsessive-compulsive patients: a SPECT study. Am. J. Psychiatry 148, 1240-1242.

Malberg, J. E., Eisch, A. J., Nestler, E. J., and Duman, R. S. (2000). Chronic antidepressant treatment increases neurogenesis in adult rat hippocampus. J. Neurosci. 20, 9104-9110.

Mallet, L., Mesnage, V., Houeto, J. L., Pelissolo, A., Yelnik, J., Behar, C., Gargiulo, M., Welter, M. L., Bonnet, A. M., Pillon, B., Cornu, P., Dormont, D., Pidoux, B., Allilaire, J. F., and Agid, Y. (2002). Compulsions, Parkinson's disease, and stimulation. Lancet 360, 1302-1304.

Mallet, L., Polosan, M., Jaafari, N., Baup, N., Welter, M. L., Fontaine, D., Du Montcel, S. T., Yelnik, J., Chereau, I., Arbus, C., Raoul, S., Aouizerate, B., Damier, P., Chabardes, S., Czernecki, V., Ardouin, C., Krebs, M. O., Bardinet, E., Chaynes, P., Burbaud, P., Cornu, P., Derost, P., Bougerol, T., Bataille, B., Mattei, V., Dormont, D., Devaux, B., Verin, M., Houeto, J. L., Pollak, P., Benabid, A. L., Agid, Y., Krack, P., Millet, B., and Pelissolo, A. (2008). Subthalamic nucleus stimulation in severe obsessive-compulsive disorder. N. Engl. J. Med. 359, 2121-2134.

Mallet, L., Schupbach, M., N’Diaye, K., Remy, P., Bardinet, E., Czernecki, V., Welter, M. L., Pelissolo, A., Ruberg, M., Agid, Y., and Yelnik, J. (2007). Stimulation of subterritories of the subthalamic nucleus reveals its role in the integration of the emotional and motor aspects of behavior. Proc. Natl. Acad. Sci. U.S.A. 104, 10661-10666.

Maltby, N., Tolin, D. F., Worhunsky, P., O'Keefe, T. M., and Kiehl, K. A. (2005). Dysfunctional action monitoring hyperactivates frontal-striatal circuits in obsessive-compulsive disorder: an event-related fMRI study. Neuroimage 24, 495-503.

Maren, S., and Quirk, G. J. (2004). Neuronal signalling of fear memory. Nat. Rev. Neurosci. 5, 844-852.

Maurice, N., Thierry, A. M., Glowinski, J., and Deniau, J. M. (2003). Spontaneous and evoked activity of substantia nigra pars reticulata neurons during high-frequency stimulation of the subthalamic nucleus. J. Neurosci. 23, 9929-9936.

McCracken, C. B., and Grace, A. A. (2007). High-frequency deep brain stimulation of the nucleus accumbens region suppresses neuronal activity and selectively modulates afferent drive in rat orbitofrontal cortex in vivo. J. Neurosci. 27, 12601-12610.

McCracken, C. B., and Grace, A. A. (2009). Nucleus accumbens deep brain stimulation produces regionspecific alterations in local field potential oscillations and evoked responses in vivo. J. Neurosci. 29, 5354-5363.

McGuire, P. K., Bench, C. J., Frith, C. D., Marks, I. M., Frackowiak, R. S., and Dolan, R. J. (1994). Functional anatomy of obsessive-compulsive phenomena. Br. J. Psychiatry 164, 459-468.

McIntyre, C. C., and Grill, W. M. (1999). Excitation of central nervous system neurons by nonuniform electric fields. Biophys. J. 76, 878-888.

McIntyre, C. C., Grill, W. M., Sherman, D. L., and Thakor, N. V. (2004). Cellular effects of deep brain stimulation: model-based analysis of activation and inhibition. J. Neurophysiol. 91, 1457-1469.

McNeal, D. R. (1976). Analysis of a model for excitation of myelinated nerve. IEEE Trans. Biomed. Eng. 23, 329-337.

Meissner, W., Leblois, A., Hansel, D., Bioulac, B., Gross, C. E., Benazzouz, A., and Boraud, T. (2005). Subthalamic high frequency stimulation resets subthalamic firing and reduces abnormal oscillations. Brain 128, 2372-2382.

Mian, M. K., Campos, M., Sheth, S. A., and Eskandar, E. N. (2010). Deep brain stimulation for obsessivecompulsive disorder: past, present, and future. Neurosurg. Focus 29, E10.
Milad, M. R., and Rauch, S. L. (2007). The role of the orbitofrontal cortex in anxiety disorders. Ann. N.Y. Acad. Sci. 1121, 546-561.

Milad, M. R., and Rauch, S. L. (2011). Obsessive-compulsive disorder: beyond segregated cortico-striatal pathways. Trends Cogn. Sci. 16, 43-51.

Miocinovic, S., Parent, M., Butson, C. R., Hahn, P. J., Russo, G. S., Vitek, J. L., and McIntyre, C. C. (2006). Computational analysis of subthalamic nucleus and lenticular fasciculus activation during therapeutic deep brain stimulation. J. Neurophysiol. 96, 1569-1580.

Modell, J. G., Mountz, J. M., Curtis, G. C., and Greden, J. F. (1989). Neurophysiologic dysfunction in basal ganglia/limbic striatal and thalamocortical circuits as a pathogenetic mechanism of obsessive-compulsive disorder. J. Neuropsychiatry Clin. Neurosci. 1, 27-36.

Mundt, A., Klein, J., Joel, D., Heinz, A., Djodari-Irani, A., Harnack, D., Kupsch, A., Orawa, H., Juckel, G., Morgenstern, R., and Winter, C. (2009). High-frequency stimulation of the nucleus accumbens core and shell reduces quinpiroleinduced compulsive checking in rats. Eur. J. Neurosci. 29, 2401-2412.

Nowak, L. G., and Bullier, J. (1998). Axons, but not cell bodies, are activated by electrical stimulation in cortical gray matter. II. Evidence from selective inactivation of cell bodies and axon initial segments. Exp. Brain Res. 118, 489-500.

Nuttin, B., Cosyns, P., Demeulemeester, H., Gybels, J., and Meyerson, B. (1999). Electrical stimulation in anterior limbs of internal capsules in patients with obsessivecompulsive disorder. Lancet 354, 1526.

Nuttin, B. J., Gabriels, L. A., Cosyns, P. R., Meyerson, B. A., Andreewitch, S., Sunaert, S. G., Maes, A. F., Dupont, P. J., Gybels, J. M., Gielen, F., and Demeulemeester, H. G. (2003). Long-term electrical capsular stimulation in patients with obsessive-compulsive disorder. Neurosurgery 52, 1263-1272. discussion 1272-1274.

Okun, M. S., Mann, G., Foote, K. D., Shapira, N. A., Bowers, D., Springer, U., Knight, W., Martin, P., and Goodman, W. K. (2007). Deep brain stimulation in the internal capsule and nucleus accumbens region: responses observed during active and sham programming. $J$. Neurol. Neurosurg. Psychiatry 78, 310-314. 
Pahapill, P. A., Levy, R., Dostrovsky, J. O., Davis, K. D., Rezai, A. R., Tasker, R. R., and Lozano, A. M. (1999). Tremor arrest with thalamic microinjections of muscimol in patients with essential tremor. Ann. Neurol. 46, 249-252.

Perani, D., Colombo, C., Bressi, S., Bonfanti, A., Grassi, F., Scarone, S., Bellodi, L., Smeraldi, E., and Fazio, F. (1995). [18F]FDG PET study in obsessive-compulsive disorder. A clinical/metabolic correlation study after treatment. Br. J. Psychiatry 166, 244-250.

Pothuizen, H. H., Jongen-Relo, A. L., Feldon, J., and Yee, B. K. (2005). Double dissociation of the effects of selective nucleus accumbens core and shell lesions on impulsive-choice behaviour and salience learning in rats. Eur. J. Neurosci. 22, 2605-2616.

Rattay, F. (1986). Analysis of models for external stimulation of axons. IEEE Trans. Biomed. Eng. 33, 974-977.

Rattay, F. (1999). The basic mechanism for the electrical stimulation of the nervous system. Neuroscience 89, 335-346.

Rauch, S. L., Dougherty, D. D., Malone, D., Rezai, A., Friehs, G., Fischman, A. J., Alpert, N. M., Haber, S. N., Stypulkowski, P. H., Rise, M. T., Rasmussen, S. A., and Greenberg, B. D. (2006). A functional neuroimaging investigation of deep brain stimulation in patients with obsessivecompulsive disorder. J. Neurosurg. 104, 558-565.

Rauch, S. L., Jenike, M. A., Alpert, N. M., Baer, L., Breiter, H. C., Savage, C. R., and Fischman, A. J. (1994). Regional cerebral blood flow measured during symptom provocation in obsessive-compulsive disorder using oxygen 15-labeled carbon dioxide and positron emission tomography. Arch. Gen. Psychiatry $51,62-70$.

Robinson, D., Wu, H., Munne, R. A., Ashtari, M., Alvir, J. M., Lerner, G., Koreen, A., Cole, K., and Bogerts, B. (1995). Reduced caudate nucleus volume in obsessive-compulsive disorder. Arch. Gen. Psychiatry 52, 393-398.

Rotge, J. Y., Guehl, D., Dilharreguy, B., Cuny, E., Tignol, J., Bioulac, B., Allard, M., Burbaud, P., and Aouizerate, B. (2008). Provocation of obsessive-compulsive symptoms: a quantitative voxel-based metaanalysis of functional neuroimaging studies. J. Psychiatry Neurosci. 33, 405-412.

Rotge, J. Y., Langbour, N., Guehl, D., Bioulac, B., Jaafari, N., Allard, M., Aouizerate, B., and Burbaud,
P. (2010). Gray matter alterations in obsessive-compulsive disorder: an anatomic likelihood estimation meta-analysis. Neuropsychopharmacology 35, 686-691.

Santarelli, L., Saxe, M., Gross, C., Surget, A., Battaglia, F., Dulawa, S., Weisstaub, N., Lee, J., Duman, R., Arancio, O., Belzung, C., and Hen, R. (2003). Requirement of hippocampal neurogenesis for the behavioral effects of antidepressants. Science 301, 805-809.

Saxena, S., Brody, A. L., Maidment, K. M., Smith, E. C., Zohrabi, N., Katz, E., Baker, S. K., and Baxter, L. R. Jr. (2004). Cerebral glucose metabolism in obsessive-compulsive hoarding. Am. J. Psychiatry 161, 1038-1048.

Saxena, S., Brody, A. L., Schwartz, J. M., and Baxter, L. R. (1998). Neuroimaging and frontalsubcortical circuitry in obsessivecompulsive disorder. Br. J. Psychiatry Suppl. 35, 26-37.

Saxena, S., and Rauch, S. L. (2000). Functional neuroimaging and the neuroanatomy of obsessivecompulsive disorder. Psychiatr. Clin. North Am. 23, 563-586.

Scarone, S., Colombo, C., Livian, S., Abbruzzese, M., Ronchi, P., Locatelli, M., Scotti, G., and Smeraldi, E. (1992). Increased right caudate nucleus size in obsessivecompulsive disorder: detection with magnetic resonance imaging. Psychiatry Res. 45, 115-121.

Schlosser, R. G., Wagner, G., Schachtzabel, C., Peikert, G., Koch, K., Reichenbach, J. R., and Sauer, H. (2010). Fronto-cingulate effective connectivity in obsessive compulsive disorder: a study with fMRI and dynamic causal modeling. Hum. Brain Mapp. 31, 1834-1850.

Schwartz, J. M., Stoessel, P. W., Baxter, L. R. Jr., Martin, K. M., and Phelps, M. E. (1996). Systematic changes in cerebral glucose metabolic rate after successful behavior modification treatment of obsessive-compulsive disorder. Arch. Gen. Psychiatry 53, 109-113.

Serra, F. P., Palma, V., Nolfe, G., and Buscaino, G. A. (1994). An electrophysiological study in obsessional compulsive disorders. Acta Neurol. (Napoli) 16, 240-248.

Sesack, S. R., and Grace, A. A. (2010). Cortico-Basal Ganglia reward network: microcircuitry. Neuropsychopharmacology 35, 27-47.

Sesia, T., Bulthuis, V., Tan, S., Lim, L. W., Vlamings, R., Blokland, A., Steinbusch, H. W., Sharp, T., Visser-Vandewalle, V., and Temel, Y. (2010). Deep brain stimulation of the nucleus accumbens shell increases impulsive behavior and tissue levels of dopamine and serotonin. Exp. Neurol. 225, 302-309.

Sesia, T., Temel, Y., Lim, L. W. Blokland, A., Steinbusch, H. W., and Visser-Vandewalle, V. (2008). Deep brain stimulation of the nucleus accumbens core and shell: opposite effects on impulsive action. Exp. Neurol. 214, 135-139.

Shapira, N. A., Okun, M. S., Wint, D., Foote, K. D., Byars, J. A., Bowers, D., Springer, U. S., Lang, P. J., Greenberg, B. D., Haber, S. N., and Goodman, W. K. (2006). Panic and fear induced by deep brain stimulation. J. Neurol. Neurosurg. Psychiatry 77, 410-412.

Shink, E., and Smith, Y. (1995). Differential synaptic innervation of neurons in the internal and external segments of the globus pallidus by the GABA- and glutamatecontaining terminals in the squirre monkey. J. Comp. Neurol. 358, 119-141.

Simon, D., Kaufmann, C., Musch, K., Kischkel, E., and Kathmann, N. (2010). Fronto-striato-limbic hyperactivation in obsessivecompulsive disorder during individually tailored symptom provocation. Psychophysiology 47, 728-738.

Skoog, G., and Skoog, I. (1999). A 40-year follow-up of patients with obsessive-compulsive disorder [see commetns]. Arch. Gen. Psychiatry 56, 121-127.

Stone, S. S., Teixeira, C. M., Devito, L. M., Zaslavsky, K., Josselyn, S. A., Lozano, A. M., and Frankland, P. W. (2011). Stimulation of entorhinal cortex promotes adult neurogenesis and facilitates spatial memory. J. Neurosci. 31, 13469-13484.

Sturm, V., Lenartz, D., Koulousakis, A., Treuer, H., Herholz, K., Klein, J. C., and Klosterkotter, J. (2003). The nucleus accumbens: a target for deep brain stimulation in obsessivecompulsive- and anxiety-disorders. J. Chem. Neuroanat. 26, 293-299.

Swedo, S. E., Pietrini, P., Leonard, H. L., Schapiro, M. B., Rettew, D. C., Goldberger, E. L., Rapoport, S. I., Rapoport, J. L., and Grady, C. L. (1992). Cerebral glucose metabolism in childhood-onset obsessive-compulsive disorder. revisualization during pharmacotherapy. Arch. Gen. Psychiatry 49, 690-694.

Swedo, S. E., Schapiro, M. B., Grady, C. L., Cheslow, D. L., Leonard, H. L., Kumar, A., Friedland, R., Rapoport, S. I., and Rapoport, J. L. (1989). Cerebral glucose metabolism in childhood-onset obsessive-compulsive disorder. Arch. Gen. Psychiatry 46, 518-523.

Tai, C. H., Boraud, T., Bezard, E., Bioulac, B., Gross, C., and Benazzouz, A. (2003). Electrophysiological and metabolic evidence that high-frequency stimulation of the subthalamic nucleus bridles neuronal activity in the subthalamic nucleus and the substantia nigra reticulata. FASEB J. 17, 1820-1830.

Tawfik, V. L., Chang, S. Y., Hitti, F. L., Roberts, D. W., Leiter, J. C., Jovanovic, S., and Lee, K. H. (2010). Deep brain stimulation results in local glutamate release: investigation into the role of astrocytes. Neurosurgery 67, 367-375.

Traub, R. D., Bibbig, A., Lebeau, F. E., Buhl, E. H., and Whittington, M. A. (2004). Cellular mechanisms of neuronal population oscillations in the hippocampus in vitro. Annu. Rev. Neurosci. 27, 247-278.

Tsai, H. C., Chen, S. Y., Tsai, S. T., Hung, H. Y., and Chang, C. H. (2010). Hypomania following bilateral ventral capsule stimulation in a patient with refractory obsessive-compulsive disorder. Biol. Psychiatry 68, e7-e8.

Urbano, F., Leznik, E., and Llinas, R. (2002). Cortical activation patterns evoked by afferent axons stimuli at different frequencies: an in vitro voltage-sensitive dye imaging study. Thalamus Relat. Syst. 1, 371-378.

van der Wee, N. J., Stevens, H., Hardeman, J. A., Mandl, R. C., Denys, D. A., Van Megen, H. J., Kahn, R. S., and Westenberg, H. M. (2004). Enhanced dopamine transporter density in psychotropic-naive patients with obsessive-compulsive disorder shown by [123I] \{beta\}-CIT SPECT. Am. J. Psychiatry 161, 2201-2206.

van Dijk, A., Mason, O., Klompmakers, A. A., Feenstra, M. G., and Denys, D. (2011). Unilateral deep brain stimulation in the nucleus accumbens core does not affect local monoamine release. J. Neurosci. Methods 202, 113-118.

van Kuyck, K., Brak, K., Das, J., Rizopoulos, D., and Nuttin, B. (2008). Comparative study of the effects of electrical stimulation in the nucleus accumbens, the mediodorsal thalamic nucleus and the bed nucleus of the stria terminalis in rats with scheduleinduced polydipsia. Brain Res. 1201, 93-99.

van Kuyck, K., Demeulemeester, H., Feys, H., De Weerdt, W., Dewil, M. Tousseyn, T., De Sutter, P., Gybels, J., 
Bogaerts, K., Dom, R., and Nuttin, B. (2003). Effects of electrical stimulation or lesion in nucleus accumbens on the behaviour of rats in a T-maze after administration of 8OH-DPAT or vehicle. Behav. Brain Res. 140, 165-173.

Van Laere, K., Nuttin, B., Gabriels, L., Dupont, P., Rasmussen, S., Greenberg, B. D., and Cosyns, P. (2006). Metabolic imaging of anterior capsular stimulation in refractory obsessive-compulsive disorder: a key role for the subgenual anterior cingulate and ventral striatum. J. Nucl. Med. 47, 740-747.

Welter, M. L., Houeto, J. L., Bonnet, A. M., Bejjani, P. B., Mesnage, V., Dormont, D., Navarro, S., Cornu, P., Agid, Y., and Pidoux, B. (2004). Effects of high-frequency stimulation on subthalamic neuronal activity in parkinsonian patients. Arch. Neurol. 61, 89-96.
Wichmann, T., Bergman, H., and Delong, M. R. (1994). The primate subthalamic nucleus. III. Changes in motor behavior and neuronal activity in the internal pallidum induced by subthalamic inactivation in the MPTP model of parkinsonism. J. Neurophysiol. 72, 521-530.

Windels, F., Bruet, N., Poupard, A., Urbain, N., Chouvet, G., Feuerstein, C., and Savasta, M. (2000). Effects of high frequency stimulation of subthalamic nucleus on extracellular glutamate and GABA in substantia nigra and globus pallidus in the normal rat. Eur. J. Neurosci. 12, 4141-4146.

Winter, C., Lemke, C., Sohr, R., Meissner, W., Harnack, D., Juckel, G., Morgenstern, R., and Kupsch, A. (2008a). High frequency stimulation of the subthalamic nucleus modulates neurotransmission in limbic brain regions of the rat. Exp. Brain Res. 185, 497-507.

Winter, C., Mundt, A., Jalali, R., Joel, D., Harnack, D., Morgenstern, R., Juckel, G., and Kupsch, A. (2008b). High frequency stimulation and temporary inactivation of the subthalamic nucleus reduce quinpirole-induced compulsive checking behavior in rats. Exp. Neurol. 210, 217-228.

Zheng, F., Lammert, K., NixdorfBergweiler, B. E., Steigerwald, F., Volkmann, J., and Alzheimer, C. (2011). Axonal failure during high frequency stimulation of rat subthalamic nucleus. J. Physiol. 589, 2781-2793.

Conflict of Interest Statement: The authors declare that the research was conducted in the absence of any commercial or financial relationships that could be construed as a potential conflict of interest.

Received: 01 February 2012; accepted: 24 May 2012; published online: 14 June 2012.

Citation: Bourne SK, Eckhardt CA, Sheth SA and Eskandar EN (2012) Mechanisms of deep brain stimulation for obsessive compulsive disorder: effects upon cells and circuits. Front. Integr. Neurosci. 6:29. doi: 10.3389/fnint. 2012.00029

Copyright (c) 2012 Bourne, Eckhardt, Sheth and Eskandar. This is an openaccess article distributed under the terms of the Creative Commons Attribution Non Commercial License, which permits non-commercial use, distribution, and reproduction in other forums, provided the original authors and source are credited. 